\title{
Effects of seagrass beds (Zostera noltii and Z. marina) on near-bed hydrodynamics and sediment resuspension
}

\author{
John Widdows ${ }^{1, *}$, Nick D. Pope ${ }^{1}$, Mary D. Brinsley ${ }^{1}$, Harald Asmus $^{2}$, \\ Ragnhild M. Asmus ${ }^{2}$ \\ ${ }^{1}$ Plymouth Marine Laboratory, Prospect Place, The Hoe, Plymouth PL1 3DH, UK \\ ${ }^{2}$ Alfred Wegener Institute for Polar and Marine Research, Wadden Sea Station Sylt, Hafenstrasse 43, 25992 List, Germany
}

\begin{abstract}
The main objectives of this flume study were to (1) quantify density dependent effects of the short-leaf seagrass Zostera nolti on hydrodynamics and sediment resuspension from a sandy bed, and (2) measure the erodability of 2 contrasting sediments (sandy and muddy) and the extent to which this is modified by the presence of 2 seagrass species, $Z$. noltii (sandy) and $Z$. marina (muddy). Field measurements of near-bed tidal currents, turbulence and suspended particulate matter at 2 different $Z$. noltii locations (low energy [sheltered] and higher energy [exposed] environments) were interpreted in the context of the flume results. Skimming flow above the high density bed of $Z$. noltii was accompanied by a $40 \%$ reduction in near-bed flow, but this was offset by a 2 -fold increase in turbulent kinetic energy (TKE) and bed shear stress $\left(\tau_{0}\right)$. Despite this increase in $\tau_{0}$ there was an increase in sediment stabilisation with increasing seagrass density (10-fold increase in critical bed shear stress for erosion $\left[\tau_{\mathrm{e}}\right.$ ] from 0.1 [bare sediment] to $1.0 \mathrm{~Pa}$ at the highest shoot density). This was largely explained by the increased microphytobenthos abundance (reflected in the higher chlorophyll $a$ and carbohydrate contents) and a lower density of the grazer and bio-destabiliser Hydrobia ulvae. In contrast, the muddy site was more easily eroded (10-fold higher), with $Z$. marina having little effect on sediment erodability (bare: $\tau_{\mathrm{e}}=0.05 \mathrm{~Pa} ; Z$. marina: $\tau_{\mathrm{e}}=0.07 \mathrm{~Pa}$ ). This higher erodability was due to differences in hydrodynamics and the physical/biological properties of the sediment.
\end{abstract}

KEY WORDS: Seagrass beds - Zostera noltii - Zostera marina $\cdot$ Hydrodynamics $\cdot$ Sediment resuspension Resale or republication not permitted without written consent of the publisher

\section{INTRODUCTION}

It is well established that hydrodynamics and sediment dynamics can be modified by a wide range of biota and biological processes (Rhoads \& Boyer 1982, Paterson \& Black 1999, Widdows \& Brinsley 2002). Biota acting as 'stabilisers' can reduce sediment resuspension, enhancing sediment stability by increasing cohesiveness, binding surface sediments (filaments and root systems), physical protection of sediment surface, and flow attenuation by currents and waves. Other biota, acting as destabilisers, can enhance sediment erodability by increasing bed roughness and near-bed turbulence, loosening surface sediments by bioturbation, and grazing on biostabilisers such as algal biofilms (trophic interactions).

Macrophytes, including seagrass beds, are not only affected by but also modify hydro- and sediment dynamics (Madsen et al. 2001). Previous studies have shown that seagrass beds influence mean flow (Gambi et al. 1990), turbulence (Gambi et al. 1990, Koch 1994), waves (Koch 1999, Koch \& Gust 1999) and hydrodynamics at horizontal spatial scales (Granata et al. 2001). Currents and waves attenuated by seagrass and other macrophytes tend to create a low-energy environment which can enhance deposition, reduce sedi- 
ment resuspension, and thus create habitat stability (Madsen et al. 2001). To date, most investigations have focused on aspects of hydrodynamics, using flume studies and field measurements to quantify the attenuation of currents and waves by a variety of long-leaf seagrass beds, including Zostera marina (Fonseca et al. 1982, Fonseca \& Fisher 1986, Gambi et al. 1990), Ruppia maritima (Ward et al. 1984), Syringodium filiforme (Fonseca \& Fisher 1986), Thalassia testudinum (Fonseca \& Fisher 1986, Koch 1999, Koch \& Gust 1999), Halodule wrightii (Fonseca \& Fisher 1986), Z. novazelandica (Heiss et al. 2000), Posidonia oceanica (Granata et al. 2001), Amphibolis griffithii, P. australis and P. sinuosa (van Keulen \& Borowitzka 2002). In a comparative study, Fonseca \& Fisher (1986) examined density dependent effects of seagrass species with long shoots, for example, T. testudinum (13 to $20 \mathrm{~cm})$, $H$. wrightii (15 to $20 \mathrm{~cm}), Z$. marina (18 to $20 \mathrm{~cm}$ ), and $S$. filiforme (24 to $26 \mathrm{~cm}$ ). They concluded that all seagrasses could not be categorised into a single functional group since each had a different canopy friction related to the proportion of the water column occupied by the seagrasses and the degree of protection provided against bed erosion.

A reduction in current velocities within seagrass beds is usually accompanied by skimming flow, an increase in flow above the seagrass canopies relative to ambient flow (Fonseca et al. 1982, Fonseca 1983, Ackerman 1986, Gambi et al. 1990, Koch 1994). When the seagrasses occupy the entire water column, current velocities are efficiently reduced (Ward et al. 1984, Fonseca \& Fisher 1986) and sediments tend to accumulate (Fonseca 1996). In contrast, when the water depth is greater than the maximum meadow height, wave attenuation is less efficient, and sediment is deposited as well as resuspended (Ward et al. 1984). In addition, some species have an uneven vertical biomass distribution and there is less resistance to water flow near the bed, which can lead to flow intensification near the sediment surface. Ward et al. (1984) reported significant wave induced resuspension in shallow waters, with less resuspension in seagrass beds compared to unvegetated areas. In an in situ flume study, Asmus \& Asmus (2000) showed that dense seagrass beds (Zostera marina) act as a sink for particulate organic matter in comparison to bare controls. Gacia \& Duarte (2001), using sediment traps, showed that Posidonia oceanica meadows significantly reduce sediment resuspension by $>3$-fold compared to unvegetated areas, and thus increased sediment retention.

Although there have been many extensive studies on seagrass beds, a relatively small number of these quantify the relationship between seagrass density and sediment erodability in response to varying flow regimes. In particular, there are very few studies on the effects of the short-leaf seagrass (dwarf eelgrass Zostera noltii) on flow attenuation and sediment erodability. This small seagrass species, which occurs in intertidal and subtidal areas of northern and western Europe, the Mediterranean Sea and northwest Africa, grows in a range of habitats from sheltered low energy environments to higher energy environments with stronger tidal flows and more wave activity. For $Z$. noltii living in the Wadden Sea, the main period of vegetative growth occurs during July, August and September and leaf cover declines in the autumn and winter; this species may experience complete loss of foliage in the winter, dying back to the buried rhizome.

Vegetation height, density and leaf/stem flexibility are important factors determining the dissipation of currents and wave energy and the extent to which sediment erosion is reduced. Bouma et al. (2005) showed that stiff stems (e.g. Spartina anglica) were 3 times more effective at absorbing wave energy than flexible vegetation (e.g. Zostera noltii), and both demonstrated a $\sim 4$-fold increase in wave dissipation with an order of magnitude increase in plant density. Amos et al. (2004) conducted in situ flume measurements of sediment resuspension in the Venice lagoon and showed that sites with $Z$. noltii ( 20 to $60 \%$ coverage of the bed) increased the critical erosion threshold $\left(\tau_{\mathrm{e}}\right)$ by up to 4 -fold.

Any increased sediment stability associated with seagrass beds tends to reduce the turbidity of shallow coastal waters, and thus increases light penetration in the water column and contributes to a positive feedback on the growth and productivity of seagrass beds. Water movement has been shown to have a strong influence on seagrass production, growth rate and photosynthesis (Fonseca \& Kenworthy 1987, Peralta et al. 2006). Controlled flume studies by Peralta et al. (2006) have demonstrated that increased flow (between 0.01 and $0.35 \mathrm{~m} \mathrm{~s}^{-1}$ ) has a direct and positive effect on Zostera noltii in terms of increased growth, leaf cross section, root length per plant, and below ground to above ground ratio. An increase in belowground tissues (root/rhizomes) in high hydrodynamic environments has also been shown in situ for $Z$. marina and Halodule wrightii (Fonseca \& Bell 1988) and for $Z$. noltii (Peralta et al. 2005). Seagrasses therefore adapt to high velocity environments by (1) improving the anchorage system within potentially mobile or erodable sediments, and (2) reducing the risk of shoot breakage by reducing the leaf length and increasing the cross section of the leaves.

Zostera noltii is sensitive to changes in sediment dynamics (Cabaco \& Santos 2007) resulting from natural processes (e.g. storms and inlet migration) and/or anthropogenic activities (e.g. dredging of navigation channels, sedimentation due to land run-off). For 
example, Cabaco \& Santos (2007) showed that Z. noltii does not survive for more than $2 \mathrm{wk}$ under complete burial and because of its small size cannot tolerate burial $>4 \mathrm{~cm}$. Schanz \& Asmus (2003), using in situ experimental flumes and transplant studies in the Wadden Sea, have demonstrated that hydrodynamics are important driving forces for controlling development of $Z$. noltii. An increase in flow resulted in a decline in $Z$. noltii shoot density and shoot and leaf length. In the Wadden Sea, hydrodynamics have changed dramatically during the past century due to coastal engineering (de Jonge et al. 1993) (construction of dikes and dams, dredging of tidal channels) as well as sea level rise. This may result in increased currents and wave activity that could contribute to the loss of intertidal seagrass beds.

The main objectives of this study were to (1) quantify the effect of Zostera noltii density (biomass and leaf density) on near-bed flow and sediment resuspension in controlled flume studies, (2) measure changes in near-bed flows, turbulence and suspended particulate matter in the field at 2 different $Z$. noltii locations (sheltered or low energy environment vs. higher tidal flows and wave activity) with the aim of interpreting field data in the context of the flume results, and (3) measure the erodability of 2 contrasting sediments (sandy and muddy sites) and the extent to which this is modified by the presence of seagrass species $Z$. noltii (short leaves), and Z. marina (long leaves) respectively.

\section{MATERIALS AND METHODS}

Study sites. Three seagrass beds were studied at intertidal locations on the island of Sylt in the German part of the Wadden Sea (North Sea) in July 2005 (Fig. 1). All seagrass beds were at approximately mid-tide level $(6 \mathrm{~h}$ air exposure per tide) within the shallow, enclosed embayment of Königshafen. Two seagrass beds were composed of Zostera noltii on sandy sediment (sheltered and more exposed locations), and the third seagrass bed was of $Z$. marina in a muddy area in the inner sheltered part of Königshafen. Tides were semidiurnal with a mean tidal range of $\sim 2 \mathrm{~m}$ and salinity was 32 .

Flume studies. Flume studies were conducted using the Plymouth Marine Laboratory portable annular flumes (outer diameter $64 \mathrm{~cm}$; inner diameter $44 \mathrm{~cm}$; $10 \mathrm{~cm}$ channel width; area
$0.17 \mathrm{~m}^{-2}$; max. volume $60 \mathrm{l}$; water flow was generated by 4 rotating paddles and speed controlled and data logged by a portable computer using LabView software). For details of the construction and running of the flumes see Widdows et al. (1998, 2000a) and Pope et al. (2006). Two flumes were run in parallel, enabling replicate experiments to be conducted for each experimental condition.

Bare unvegetated sediment and sediment with different densities of Zostera noltii, or a single representative density of $Z$. marina, were collected from sites in Königshafen using stainless steel quadrant box cores (4 cores forming an annulus) designed to fit precisely into the annular flumes. The quadrant cores were pushed into the sediment to a depth of $7 \mathrm{~cm}$ and dug out. Base plates were then inserted and the cores lifted for transportation to 2 flumes in the laboratory. The quadrant box cores were carefully inserted into the flumes and the stainless steel boxes removed, leaving the sediment and base plates in the flumes. The 4 sediment blocks were then carefully pushed together to fill any small gaps and the final space was filled with a slice of sediment from an additional core. This method produced a continuous bed of relatively undisturbed sediment with its surface features, stratification and natural benthic community. Previous erosion studies have demonstrated that there are no significant differences between in situ measurements and laboratory based flume measurements using quadrant box cored sediment (Widdows et al. 2000a, 2007).

The cores were collected and inserted into the flume and arranged so that there was a small bare area below

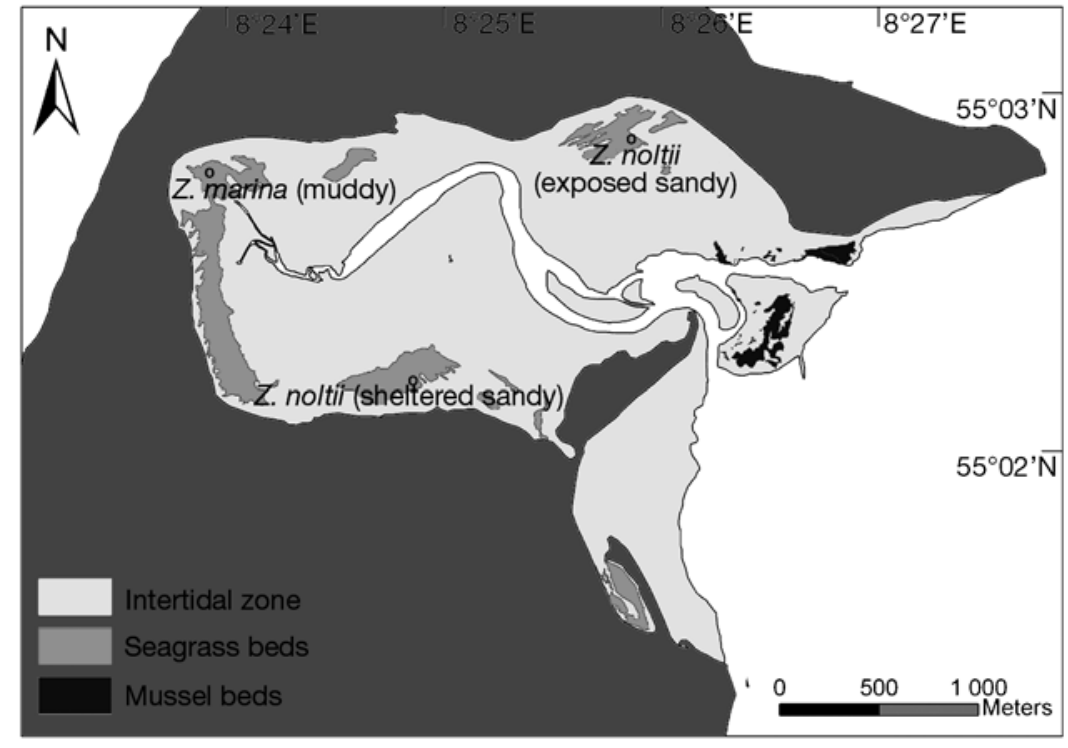

Fig. 1. Seagrass beds and sampling sites in Königshafen, Sylt, Germany 
the Acoustic Doppler Velocimeter (ADV), and the leaves of seagrass plants in the immediate vicinity did not interfere with the sampling volume of the ADV (even when bending horizontally in the flow at the highest current speeds). After inserting the sediment cores into the flume, a sheet of bubble wrap the size and shape of the annulus was carefully placed onto the sediment surface, and seawater was gently pumped onto the sheet, which then gradually floated off without disturbing the sediment surface. The flumes were then filled with $46 \mathrm{l}$ of water $(27 \mathrm{~cm}$ depth) and gently aerated to maintain fully oxygenated water prior to erosion experiments. The initial flow regime was $5 \mathrm{~cm} \mathrm{~s}^{-1}$; at the start of each experiment current speeds were increased stepwise in $5 \mathrm{~cm} \mathrm{~s}^{-1}$ increments from 5 to $40 \mathrm{~cm} \mathrm{~s}^{-1}$, with each step maintained for a period of 20 min. The suspended sediment concentration (SSC) was determined by means of frequent recording (i.e. $5 \mathrm{~s}$ intervals) of the optical backscatter sensor (OBS-3M, D \& A Instruments) mounted flush with outer flume wall. The OBS sensor was calibrated against water samples taken for gravimetric analysis during each experimental run. These samples were filtered onto pre-weighed glass fibre filters (GFC), washed with distilled water, dried at $90^{\circ} \mathrm{C}$ and re-weighed together with blank filters (calibration curves were produced for each experiment). This allowed the calculation of SSC $\left(\mathrm{mg} \mathrm{l}^{-1}\right)$, mass of sediment eroded $\left(\mathrm{g} \mathrm{m}^{-2}\right)$ and the critical erosion velocity $\left(U_{\text {crit }}, \mathrm{m} \mathrm{s}^{-1}\right)$. A Sontek micro-ADV was used in the flume to measure vertical profiles in current speed and turbulent kinetic energy (TKE) at $1 \mathrm{~mm}$ intervals from $0.3 \mathrm{~cm}$ to $1 \mathrm{~cm}$ above the bed, and at $2 \mathrm{~mm}$ intervals from 1 to $2 \mathrm{~cm}$, and then at $1 \mathrm{~cm}$ intervals to $10 \mathrm{~cm}$ above the bed (Pope et al. 2006). The velocity profile was recorded for $20 \mathrm{~s}$ at $1 \mathrm{~Hz}$ and turbulence was sampled at $25 \mathrm{~Hz}$ for 4096 values. Bed shear stress $\left(\tau_{0}\right)$ was calculated from TKE at depth $z=0.5 \mathrm{~cm}$.

Sediment properties. Physical and biological sediment properties were determined for each site. Surface sediment was cored ( $5 \mathrm{~cm}$ diameter, $1 \mathrm{~cm}$ depth, $\mathrm{n}=3$ ) and analysed for grain size distribution (BeckmanCoulter Laser Diffraction Particle Size Analyser LS 230), bulk density (mass of wet sediment/volume of wet sediment), \% water content (mass of water/mass of wet sediment) and \% particulate organic matter (POM; loss on combustion at $450^{\circ} \mathrm{C}$ ). Biological sediment properties, such as microphytobenthos biomass and extracellular polymeric substances (EPS), were measured in terms of chlorophyll a ( $\mathrm{chl} a)$ and colloidal carbohydrate content. These were measured in the top $2 \mathrm{~mm}$ of sediment, collected with cut plastic syringes of $12.5 \mathrm{~mm}$ diameter (3 replicate cores). Chl a was analysed by fluorometry following acetone extraction (Lucas et al. 2000), and EPS by the phenol-sulphuric acid method (Underwood et al. 1995).
Macrofauna abundance and biomass within the seagrass beds was dominated by the deposit-feeding gastropod Hydrobia ulvae and the cockle Cerastoderma edule. The density of $H$. ulvae was estimated by counting the number of snails on the seagrass plants, flume walls and sediment surface. $H$. ulvae rapidly emerge from the sediment immediately after inundation and the numbers were counted prior to the initiation of erosion of sediments. Cockles were counted at the end of the erosion experiments when the sediment was removed from the flumes. Seagrass densities in the flume and field studies were quantified in terms of biomass (g wet weight $\mathrm{m}^{-2}$ ) and leaves $\mathrm{m}^{-2}$ rather than shoots $\mathrm{m}^{-2}$ because in Zostera noltii leaves originate from the rhizome in groups of 2 to 5 .

Hydrodynamic measurements. Field measurements of currents, TKE, water depth and suspended particulate matter were made at 4 sites at the sheltered location (Zostera noltii densities $=0$, 97.9, 248.2, $442 \mathrm{~g}$ wet wt $\mathrm{m}^{-2}$ ) and a single site at the exposed location (Z. noltii density $=290 \mathrm{~g}$ wet $\mathrm{wt} \mathrm{m}^{-2}$ ). Measurements were made every 15 min throughout the tidal cycle using a field version of the $16 \mathrm{MHz}$ Sontek MicroADV coupled to a Sontek Hydra data logger together with a turbidity sensor (OBS-3). The ADV probe was deployed in a downward looking orientation with the sample volume at $5 \mathrm{~cm}$ above the bed. Bed shear stress was estimated from TKE using a proportionality constant of 0.19 (Stapleton \& Huntley 1995, Pope et al. 2006). The ADV within the seagrass bed was located in a small bare area so that no seagrass leaves entered the sampling volume of the ADV regardless of flow direction.

The relationships between physical, chemical and biological sediment properties were analysed using a Pearson product moment correlation coefficient. Significant differences between treatments and sites were tested using ANOVA (Minitab v. 13).

\section{RESULTS}

\section{Sediment properties}

The physical and biological sediment properties of sampling sites with Zostera noltii and Z marina beds are summarised in Table 1 . There were marked differences between the sandy and muddy sampling sites within Königshafen. In comparison to the muddy sites, the bulk densities, median grain sizes and EPS contents were significantly higher at the sandy sites, whereas the \% mud $(<63 \mu \mathrm{m}), \%$ POM, \% water and chl a contents were significantly lower (ANOVA: p < 0.0001). Within the different sediment types (i.e. sandy and muddy) there were significant increases in \% fine 


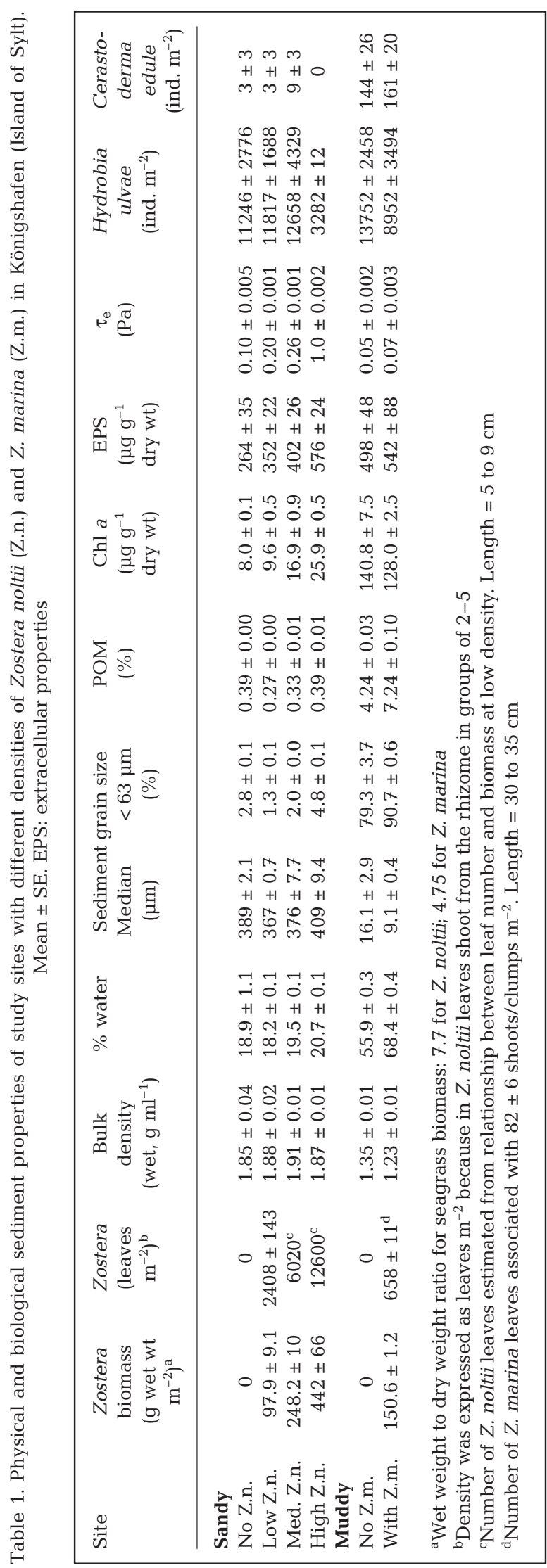

mud at locations with higher densities of $Z$. noltii and $Z$. marina ( $\mathrm{p}<0.0001)$. There was also a significant linear increase in chl a content with increasing $Z$. noltii density at the sandy site $(r=0.99, p<0.0001$; Fig. 2).

\section{Near-bed hydrodynamics}

The near-bed current velocity profiles for the bare sandy sediment (zero density) and the high density seagrass bed (Zostera noltii) are illustrated in Fig. 3a,b. The bare sediment only affected the vertical profile of currents within 0 to $7 \mathrm{~mm}$ of the bed. However, at current speeds above $0.25 \mathrm{~m} \mathrm{~s}^{-1}$ the bed began to move and sand ripples migrated around the flume. This continually moving bed thus prevented the measurement of a vertical profile close to the bed. In contrast, the beds with $Z$. noltii were more stable but showed more complex vertical profiles due to the flexing of the leaves and the development of skimming flow when free-stream velocities were $>0.15 \mathrm{~m} \mathrm{~s}^{-1}$ (Fig. 3b). This was more apparent with increasing current speed, and as the seagrass flexed in response to the current, the leaves became horizontal in the water column and increased flow occurred above the vegetation (i.e. skimming flow) at a height of $\sim 1.5 \mathrm{~cm}$ above the bed. The high density seagrass bed formed a dense layer of vegetation, which protected the bed from the elevated currents in the skimming flow. Despite this reduction in near-bed flow, at current speeds $>0.1 \mathrm{~m} \mathrm{~s}^{-1}$ there was evidence of a marked increase in shear stress below the vegetation and within the boundary layer at $z=0.5 \mathrm{~cm}$ (Fig. 4). Therefore, while depth-averaged and near-bed $(0.5 \mathrm{~cm})$ current velocities were markedly reduced (30 and $40 \%$, respectively) by higher densities of $Z$. noltii, this was offset by the 2 -fold increase in TKE and bed shear stress (Fig. 5).

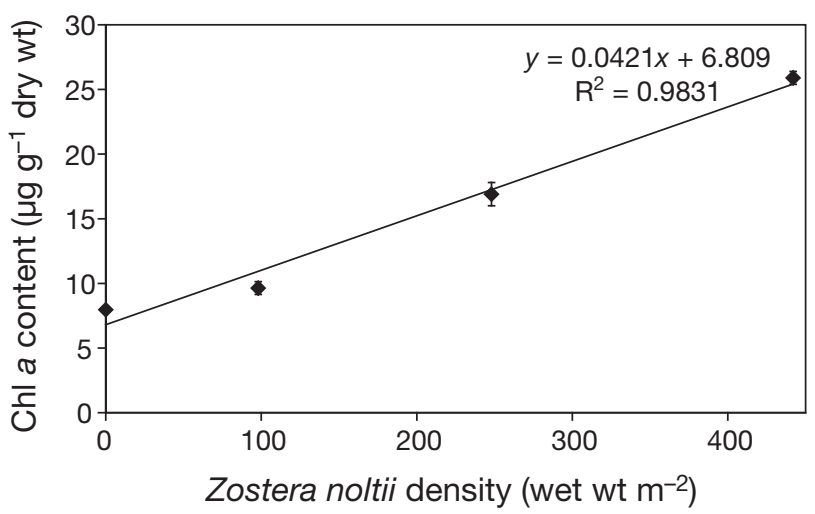

Fig. 2. Zostera noltii. Linear relationship between chl a content ( $\mu \mathrm{g} \mathrm{g}^{-1}$ dry weight; mean $\pm \mathrm{SE}$ ) and density (biomass as wet weight $\mathrm{m}^{-2}$ ) at the sandy site in Königshafen 
The vertical $(z)$ component of the velocity profiles increased with the addition of vegetation. It reached maximum values at the top of the canopy (i.e. 1.5 to $2 \mathrm{~cm}$ height) and increased with shoot density (data not shown). At a flume speed of $11 \mathrm{rpm}$ (i.e. depth aver-

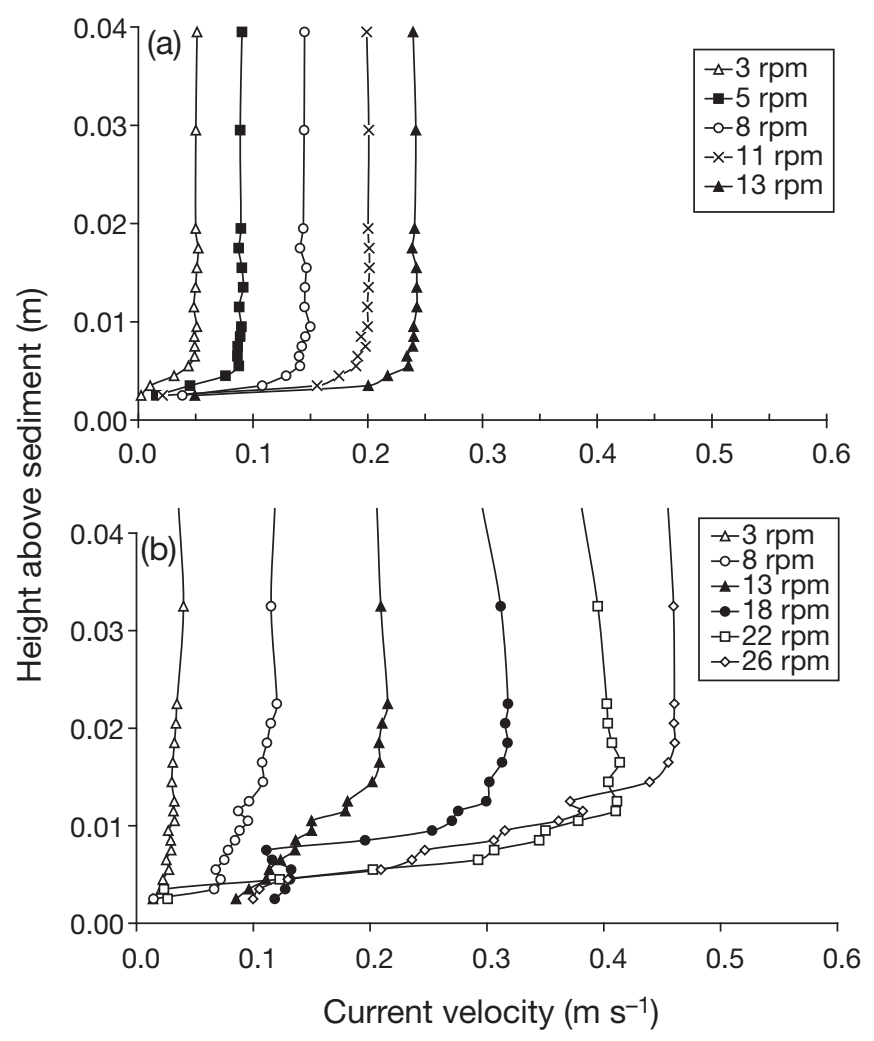

Fig. 3. Zostera noltii. Near-bed current velocity profiles (a) at 5 flume speeds (rpm) for bare sandy sediment at the $Z$. noltii site (zero density); (b) at 6 flume speeds (rpm) for high density seagrass bed (442 $\mathrm{g}$ wet $\mathrm{wt} \mathrm{m}^{-2} \equiv 12600$ leaves $\mathrm{m}^{-2}$ )

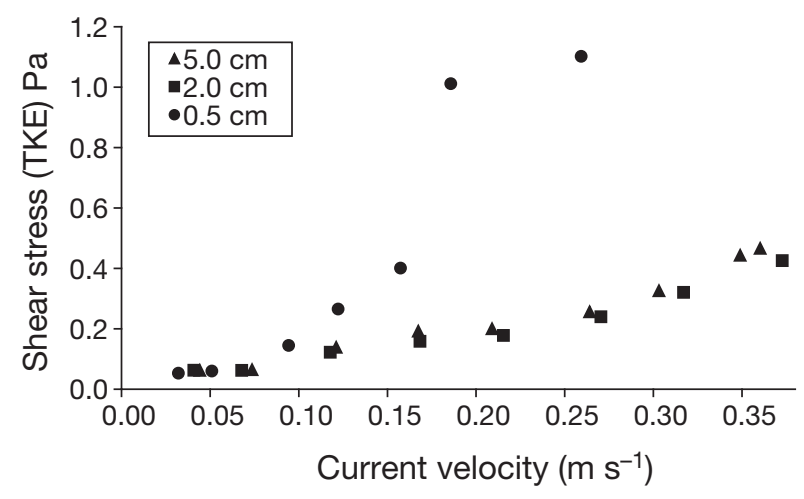

Fig. 4. Zostera noltii. Relationship between shear stress (derived from TKE) and current velocity at different heights above bed $(0.5,2.0$ and $5.0 \mathrm{~cm})$ for the high density seagrass bed (442 g wet wt $\mathrm{m}^{-2} \equiv 12600$ leaves $\mathrm{m}^{-2}$ ) aged current speed of $0.2 \mathrm{~m} \mathrm{~s}^{-1}$ at zero density), the $z$ component increased by a factor of 5 at the highest Zostera noltii density. The flow structure just above an unconfined canopy more strongly resembled a mixing layer than a boundary layer.

The single density of Zostera marina used in this study had a lesser effect on water flow within the flume and only reduced current speeds by $18 \%$ at the low flows $\left(0.05 \mathrm{~m} \mathrm{~s}^{-1}\right)$ and $8 \%$ at the higher flows $\left(0.25 \mathrm{~m} \mathrm{~s}^{-1}\right)$, whether at 0.5 or $10 \mathrm{~cm}$ height in the water column. The vertical profiles of current velocities were relatively constant at heights above $1 \mathrm{~cm}$ for bare mud and above $2 \mathrm{~cm}$ for $Z$. marina (data not shown). Any deviation from a relatively constant vertical profile only occurred at currents $>0.20 \mathrm{~m} \mathrm{~s}^{-1}$ when the leaves showed significant bending with the flow and the top of the canopy was lowered to $\sim 5 \mathrm{~cm}$ above the bed. This was reflected in a 2 -fold increase in the bed shear stress at current speeds of 0.25 and $0.30 \mathrm{~m} \mathrm{~s}^{-1}$ (Fig. 6).

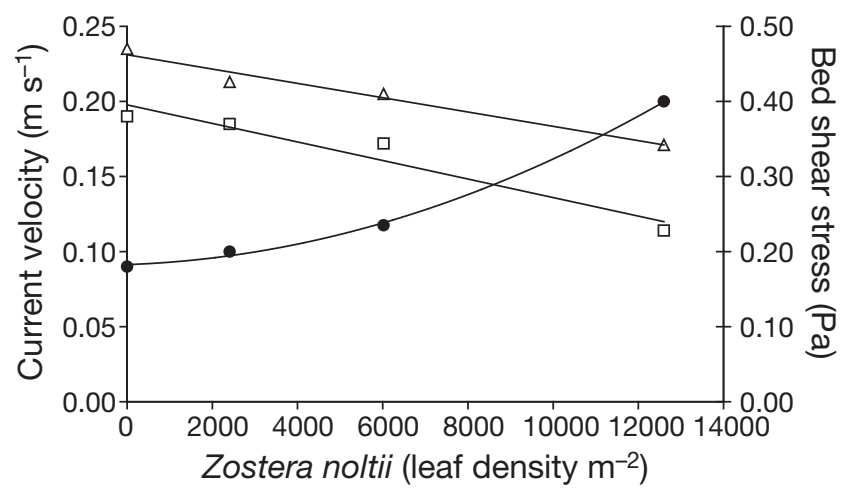

Fig. 5. Zostera noltii. Relationships between density (leaves $\mathrm{m}^{-2}$ ) and depth-averaged current velocity $(\Delta)$, current velocity at $z=0.5 \mathrm{~cm}(\square)$ and bed shear stress $(\bullet)$

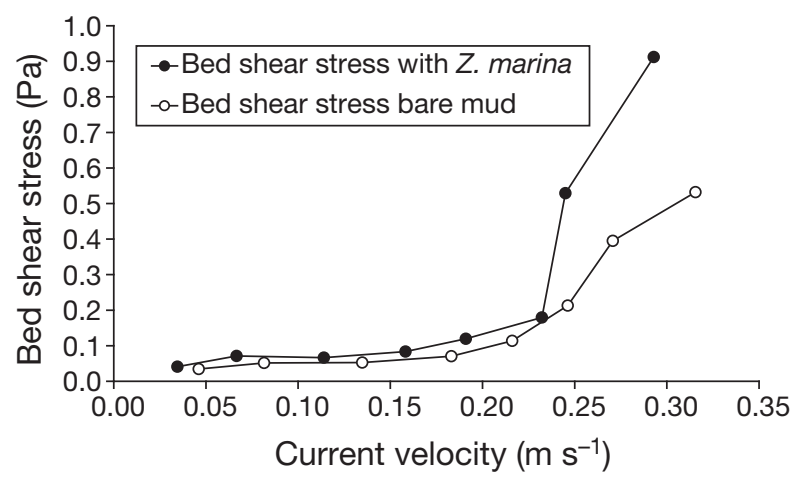

Fig. 6. Zostera marina. Relationship between bed shear stress and depth-averaged current velocity for the seagrass bed (bare mud and seagrass density of $150 \mathrm{~g}$ wet wt $\mathrm{m}^{-2}$ ) 


\section{Sediment erodability}

Sediment mass eroded plotted against depth-averaged current speed shows a similar critical erosion velocity for all Zostera noltii densities $\left(U_{\text {crit }} \sim 0.2 \mathrm{~m} \mathrm{~s}^{-1}\right.$; Fig. 7). Above $0.2 \mathrm{~m} \mathrm{~s}^{-1}$ there was the first phase of erosion, with the resupension of the fine silt and microphytobenthos associated with the surface sediments. The larger sand grains also began to move over the bed by the process of rolling or saltation. At current speeds above this threshold ( $\left.U_{\text {crit }}\right)$ then the mass of sediment eroded was inversely related to the $Z$. noltii density. At a current speed of 0.28 to $0.30 \mathrm{~m} \mathrm{~s}^{-1}$ there was a significant exponential decline in mass of sediment eroded with increasing $Z$. noltii biomass $\left(\mathrm{r}^{2}=0.91, \mathrm{p}<\right.$ 0.05 ). Above $\sim 0.25 \mathrm{~m} \mathrm{~s}^{-1}$ the bare sediment (zero density) began to move and formed migrating ripples, and under these conditions it was impossible to measure near-bed flows and turbulence at a fixed distance from the bed. At both medium and high $Z$. noltii densities, significant bed erosion and the onset of sand ripple migration occurred at depth-averaged current velocities of $>0.34 \mathrm{~m} \mathrm{~s}^{-1}$ and the mass eroded increased markedly to $136 \pm 26$ and $72 \pm 7 \mathrm{~g} \mathrm{~m}^{-2}$ (mean \pm semirange). This represented a second phase of deeper bed erosion.

When sediment mass eroded was plotted against bed shear stress there were marked differences between the critical bed shear stress of erosion for the high, medium and low Zostera noltii densities and the zero density, with an order of magnitude difference between zero and high densities (Fig. 8). If the physical and biological properties of the underlying bed were consistent, then the critical bed shear stress would usually remain relatively constant. Two biological factors likely contributed to the higher sediment stability with increasing $Z$. noltii density. Firstly, the chl a content of the surface sediment increased with $Z$. noltii density

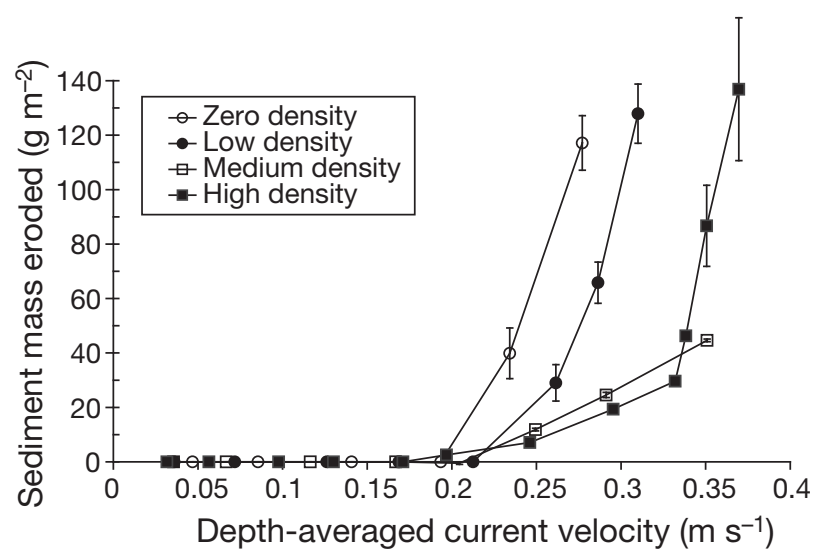

Fig. 7. Zostera noltii. Relationship between sediment mass eroded and depth-averaged current velocity for 4 densities of seagrass bed on sandy sediment (mean \pm semi-range; $\mathrm{n}=2$ )

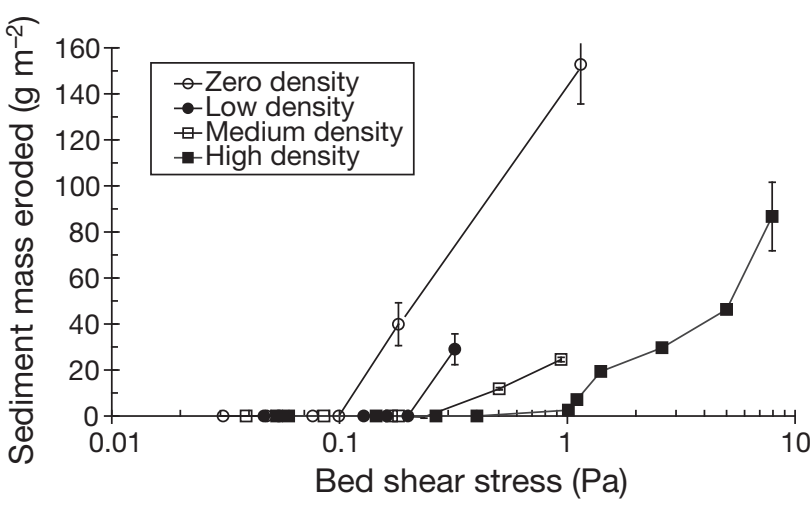

Fig. 8. Zostera noltii. Relationship between sediment mass eroded and bed shear stress (log scale) for 4 densities of seagrass bed on sandy sediment (mean \pm semi-range; $\mathrm{n}=2$ )

and was 3-fold higher at the high density site compared to the bare sediment (Table 1). This reflected the higher biomass of the microphytobenthos which contributed to increased binding and cohesiveness of sediment particles through the production of EPS (Decho 2000). Consequently, there was a highly significant correlation between chl $a$ and EPS content $(\mathrm{r}=0.96, \mathrm{p}<$ 0.0001). Secondly, there was a 3 -fold lower density of the grazing and bioturbating gastropod Hydrobia ulvae at the high density $Z$. noltii site (Table 1 ). The biostabilising algal biofilm is therefore more likely to develop and persist amongst the $Z$. noltii bed, due to the more protected and stable sediments beneath the Zostera vegetation and the lower grazing pressure by $H$. ulvae. Sites with low and medium $Z$. noltii densities had similar critical erosion bed shear stresses of 0.2 and $0.26 \mathrm{~Pa}$, higher than the bare sediment $(0.1 \mathrm{~Pa})$ but lower than the high $Z$. noltii density $(1.0 \mathrm{~Pa})$. This is consistent with the lower chl a content and the higher densities of bio-destabilising macrofauna $(H$. ulvae and Cerastoderma edule) at these sites (Table 1).

The erodability of the muddy sites with and without Zostera marina was similar, but significantly greater than the sandy sites with $Z$. noltii. The sediment mass eroded at a depth-averaged mean flow of $0.25 \mathrm{~m} \mathrm{~s}^{-1}$ was more than an order of magnitude higher (Fig. 9) and the critical erosion thresholds $\left(\tau_{\mathrm{e}}\right)$ were significantly lower than at the sandy sites (ANOVA: p < 0.001). There was little difference in the critical erosion bed shear stress (bare mud: $\tau_{\mathrm{e}}=0.05 \mathrm{~Pa}_{\text {; }}$ mud with $Z$. marina: $\tau_{\mathrm{e}}=0.07 \mathrm{~Pa}$ ) and sediment resuspension with and without $Z$. marina (Fig. 10), indicating that the presence of seagrass beds had little effect on the erodability of the muddy sediment. Faecal pellets, mucus strands and flocs (presumably derived from Hydrobia ulvae and Cerastoderma edule) were dominant components of the resuspended surface sediment at both muddy sites (with and without $Z$. marina). 


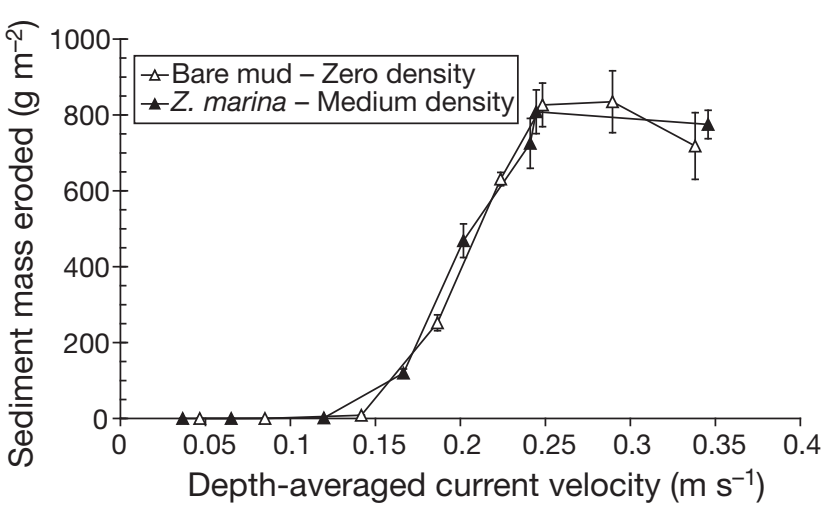

Fig. 9. Zostera marina. Relationship between sediment mass eroded and depth-averaged current velocity for the seagrass bed and muddy bare sediment (mean \pm semi-range; $\mathrm{n}=2$ )

Physical and biological properties contributing towards the lower sediment stability at the muddy site include the high water content, lower bulk density, smaller grain size, lower EPS content, and the high densities of the bio-destabilising macrofauna, such as the cockle $C$. edule and the gastropod $H$. ulvae. Clearly, the high chl a content in the surface mud suggests that the sediment had probably not been disturbed or eroded recently, thus allowing the algal biofilm to develop, but this was unable to significantly counteract the destabilising influences at the $Z$. marina site. In addition, the biomass of $Z$. marina at the muddy site was lower than the high and medium $Z$. noltii densities at the sandy site (Table 1), despite the longer leaves of $Z$. marina. Therefore, their impact on sediment stability was less because the near-bed flow was amongst the low density shoots, rather than displaced above the long shoots in the form of skimming flow. The lack of a continuing exponential increase in sediment erosion above $0.25 \mathrm{~m} \mathrm{~s}^{-1}$ was atypical and may reflect the change in the nature of the sediment strength with depth.

\section{Field measurements of hydrodynamics}

Field measurements at the 4 sampling sites at the sheltered sandy location used for the flume studies (i.e. bare, low, medium and high Zostera noltii densities) showed low values for tidal currents, bed shear stress $\left(\tau_{0}\right)$ and suspended particulate matter (SPM). The changes in water depth, current velocity, bed shear stress and SPM over a spring tidal cycle at the high density sites are illustrated in Fig. 11. At all the sheltered sandy sites (high $Z$. noltii density to zero density) values were low, with currents $<0.082 \mathrm{~m} \mathrm{~s}^{-1}, \tau_{0}<$ $0.22 \mathrm{~Pa}$ and $\mathrm{SPM}<6 \mathrm{mg} \mathrm{l}^{-1}$. The relationships between near-bed current velocity and bed shear stress over a

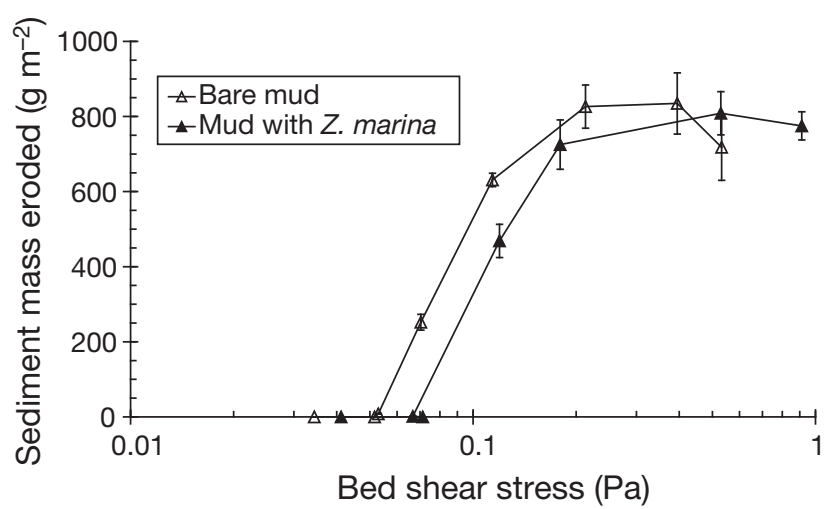

Fig. 10. Zostera marina. Relationship between sediment mass eroded and bed shear stress (log scale) for the seagrass bed and muddy bare sediment (mean \pm semi-range; $\mathrm{n}=2$ )

tidal cycle at the high and zero density sites only are illustrated in Fig. 12. This demonstrates that despite a $40 \%$ reduction in maximum near-bed current speeds at the high density $Z$. noltii site in comparison to the bare sand, the maximum values for bed shear stress were similar $(\sim 0.22 \mathrm{~Pa})$. These field measurements were consistent with the flume measurements (Fig. 5). There was also a significant correlation between current velocity and SPM concentration at the high density site $\left(\mathrm{r}^{2}=0.50, \mathrm{p}<0.001\right)$ with peak currents and SPM occurring on the flood and ebb tides. Fig. 12 shows the significant relationships between near-bed current velocity and bed shear stress over the tidal cycle at the sheltered location with high and zero densities of $Z$. noltii. The addition of critical erosion thresholds shows that the bare sediment experiences a brief period at the beginning of the flood tide when $\tau_{0}>\tau_{\mathrm{e}}$. However, the highest bed shear stresses experienced at the sheltered sandy site covered with low, medium and high $Z$. noltii densities corresponds to the critical erosion threshold of $0.2 \mathrm{~Pa}$ for the low and medium densities (97.9 and $248.2 \mathrm{~g}$ wet $\mathrm{wt} \mathrm{m}^{-2}$ ). Fig. 12 also includes the significant relationship between current velocity and bed shear stress for the more exposed sandy site with a $Z$. noltii density of $295 \mathrm{~g}$ wet $\mathrm{wt} \mathrm{m}^{-2}$. At this site the maximum currents were $0.19 \mathrm{~m} \mathrm{~s}^{-1}$ with a bed shear stress of 0.64 Pa, which was considerably higher than the $\tau_{\mathrm{e}}$ for the medium density but lower than the critical erosion threshold of 1.0 Pa for sediment with $Z$. noltii at high density.

\section{DISCUSSION}

The present flume and field study of Zostera noltii demonstrated a density dependent reduction in nearbed flow. This occurred despite the considerably shorter leaves $(5$ to $9 \mathrm{~cm}$ ) of the dwarf eelgrass $Z$. noltii, 

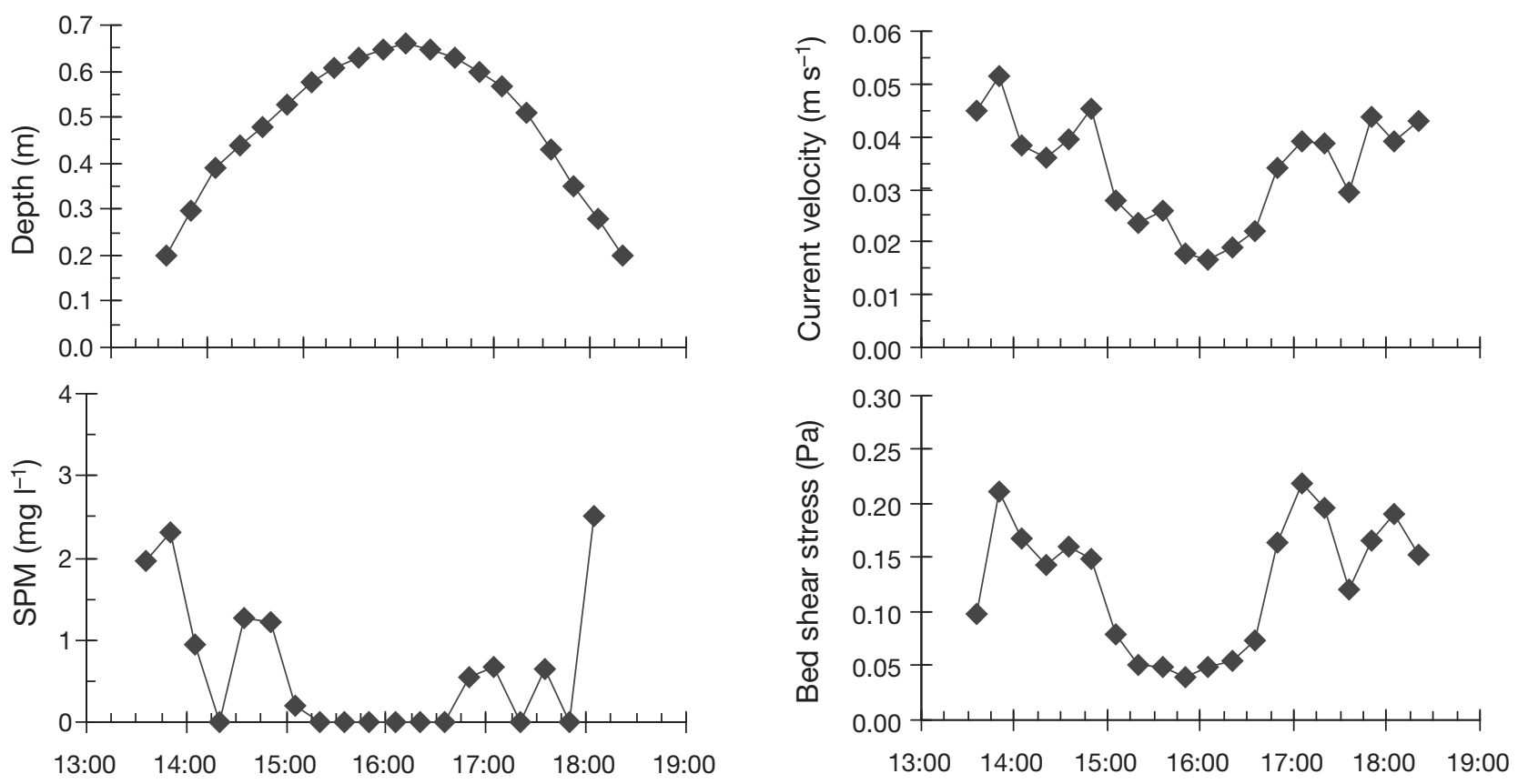

Fig. 11. Zostera noltii. Measurement of water depth (m), suspended particulate concentration (SPM, mg l-1), mean current velocity $\left(\mathrm{m} \mathrm{s}^{-1}\right)$ and bed shear stress $(\mathrm{Pa})$ over a tidal cycle within a high density seagrass bed at the sheltered sandy site in Königshafen, Sylt

compared to taller seagrass species $(20$ to $35 \mathrm{~cm}$ leaf length) which have been the subject of previous studies. The highest $Z$. noltii densities reduced current velocities of $0.2 \mathrm{~m} \mathrm{~s}^{-1}$ by $\sim 30 \%$ (inside compared to above canopy flow) and by $\sim 40 \%$ (flow at $z=0.5 \mathrm{~cm}$ inside canopy compared to bare sediment). This was comparable to the reduction in maximum flow of $40 \%$ recorded in the field (Fig. 12). A slightly higher reduction of $60 \%$ (inside compared to outside bare sedi-

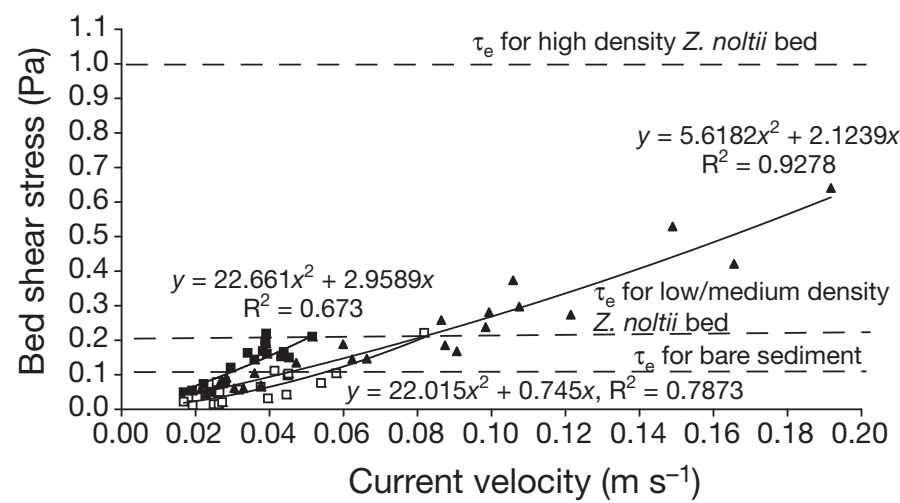

Fig. 12. Zostera noltii. Relationship between bed shear stress (Pa) and current velocity $\left(\mathrm{m} \mathrm{s}^{-1}\right)$ at the sheltered sandy site (zero [] and high densities [ם]) and at the exposed site (ム) (high density) within Königshafen, Sylt. Critical erosion thresholds $\left(\tau_{\mathrm{e}}\right)$ for bare sediment, low, medium and high density beds are highlighted ment) was recorded in the field for intertidal seagrass beds of $Z$. novazelandica with a shoot height of $12 \mathrm{~cm}$ (Heiss et al. 2000). Studies with taller seagrasses have shown a density dependent reduction in flow within the canopy (Eckman 1987, Gambi et al. 1990, Peterson et al. 2004). For example, the canopy of $Z$. marina reduced flow by 30 to $90 \%$ dependent on canopy density (400 to 1200 shoots $\mathrm{m}^{-2}$; Gambi et al. 1990). The shoot density of $Z$. marina used in the present study was $50 \%$ of the lowest density used by Gambi et al. (1990) and we only recorded an 18\% reduction at low flows. Gambi et al. (1990) also recorded a dramatic increase (10-fold) in turbulence at the canopy-water interface and within the canopy due to flow disruption by the vegetation. A comparable increase was recorded in the present study at flows $>0.2 \mathrm{~m} \mathrm{~s}^{-1}$ and at the highest density of $Z$. noltii. Field studies by Peterson et al. (2004) also showed flow attenuation in relation to the density of seagrass ( $Z$. marina ranging from 544 to 3410 shoots $\mathrm{m}^{-2}$ ). Seagrass canopies reduce current velocities with intensities proportional to the canopy height (Ward et al. 1984, Gacia et al. 1999). In this study Zostera noltii leaves flexed in response to freestream current velocities $>0.15 \mathrm{~m} \mathrm{~s}^{-1}$ and at speeds $>0.20 \mathrm{~m} \mathrm{~s}^{-1}$ the leaves were horizontal in the water column at a height of $\sim 1.5 \mathrm{~cm}$. The flexing served to minimize damage by reducing canopy drag and the forces acting on the shoots (Madsen et al. 2001, Fonseca et al. 
2007). The reduced near-bed flows at higher leaf densities displaced the high flows to the top of the canopy, thus creating skimming flow, which helped to protect the bed from sediment erosion.

In contrast to the present study, the majority of previous studies have focused on the impact of seagrass beds on hydrodynamics, from which they have inferred effects on suspended sediment concentration, gas and nutrient exchange, or provided some qualitative measure of entrainment. Fonseca \& Fisher (1986) demonstrated that the canopy friction was strongly related to the proportion of the water column occupied by 4 species of seagrasses and this reflected their effectiveness in inhibiting sediment movement. They suggested a critical erosion velocity of $\sim 0.3 \mathrm{~m} \mathrm{~s}^{-1}$ for sediment, but clearly this will be dependent on the biological and physical properties of the sediment (biostabilisers, bio-destabilisers, EPS, grain size, sand-silt mixture and water content). In the present study, using annular flumes, we have quantified sediment erodability in terms of critical erosion threshold and mass of sediment eroded in response to current speed and bed shear stress. There was a density dependent reduction in sediment erosion by Zostera noltii, with the highest density reducing sediment erosion by more than an order of magnitude between flows of 0.2 and $0.35 \mathrm{~m} \mathrm{~s}^{-1}$ (Fig. 7). This increased sediment stability was also reflected in the 10 -fold increase in $\tau_{\mathrm{e}}$ from 0.1 to $1.0 \mathrm{~Pa}$ with increasing shoot density. There was also a significant negative correlation between sediment mass eroded (at $\left.0.28 \mathrm{~m} \mathrm{~s}^{-1}\right)$ and chl $a(\mathrm{r}=-0.77, \mathrm{p}=0.026)$ and EPS content $(r=-0.81, p=0.014)$. However, this correlation could be a partial cause of sediment stability and/or the effect of more stable sediments within the seagrass bed, enabling the microphytobenthos to grow. It is well established that microphytobenthos stabilise muddy sediments (Paterson 1989, Sutherland et al. 1998, Widdows et al. 2006) and sandy sediments (Friend et al. 2003a,b), but it could also be a consequence of reduced sediment disturbance within the seagrass bed. The chl $a$ and EPS contents of the surface sediments within $Z$. noltii beds in Sylt (Table 1) were similar to those recorded by Friend et al. (2003a) in $Z$. noltii beds in the Ria Formosa, Portugal (chl $a=18.1$ to $45.1{\mu g^{-1}}^{-1}$ dry wt; EPS $=332$ to $854 \mu g^{-1}$ dry wt). Friend et al. (2003b) also reported a significant correlation between the critical erosion threshold (measured using a Cohesive Strength Meter) and chl $a$ and EPS for a range of habitats and sediment types, with the lowest values associated with bare sandy sediments.

In contrast to the sandy sites with Zostera noltii, sediment stability was considerably lower at the muddy site with $Z$. marina, despite the high chl a content. In addition, there was no difference between the stability of the muddy sediments with and without $Z$. marina. Recorded critical erosion velocities of $<0.15 \mathrm{~m} \mathrm{~s}^{-1}$ were at the lower end of the range of $U_{\text {crit }}$ values previously recorded for muddy sediments (Widdows et al. 2000b, 2006) and reflected bio-destabilised sediments. In the present study, the microphytobenthos associated with the surface sediments at the sandy site, and particularly the muddy site, were abundant despite the high density of Hydrobia ulvae, a major grazer and sediment destabiliser (Orvain et al. 2004, Widdows et al. 2006). However, at the $Z$. noltii and $Z$. marina sites, the $H$. ulvae might have been preferentially grazing on the epiphytes growing on the surface of the seagrass leaves rather than on the microphytobenthos.

Amos et al. (2004) conducted in situ flume measurements (Sea Carousel) of sediment resuspension at many locations within the Venice lagoon, including a few sites with Zostera noltii ( 20 to $60 \%$ coverage of the bed). They also noted the biostabilisation of sediment by microphytobenthos with measurements of chl $a$ and carbohydrate. However, their data set was incomplete and it was not possible to make a detailed comparison between sites to assess the role of microphytobenthos. Although the results were variable, they suggested that $Z$. noltii sites increased the $\tau_{\mathrm{e}}$ by up to 4 -fold during the summer compared to unvegetated sediment in the winter. The mean critical erosion thresholds were higher than the present study and ranged from 0.4 Pa (bare mudflat), 1.09 Pa (dominated by microphytobenthos) to $1.38 \mathrm{~Pa}$ ( $Z$. noltii sites). The difference between mean $\tau_{\mathrm{e}}$ for the unvegetated sediment and the seagrass bed was $\sim 4$-fold in the Amos et al. (2004) study, compared to 10 -fold in the present study, although the difference between the recorded minimum $\tau_{\mathrm{e}}$ (unvegetated) and the maximum $\tau_{\mathrm{e}}(Z$. noltii) was also 10 -fold.

The impact of Zostera noltii on near-bed currents and sediment resuspension is likely to vary seasonally due to the growth of leaves in the summer and their subsequent loss in winter. While the present measurements have been conducted during the summer period of above ground shoot development, there are no detailed measurements of the influence of $Z$. noltii root systems on sediment stability during the winter months when the shoots are minimal. Orth (1977) reported obvious erosion (10 to $20 \mathrm{~cm}$ ) and sand ripples in unvegetated areas after storm events with the roots and rhizomes of $Z$. marina exposed in areas on the edge of seagrass beds. This is similar to that observed in the flume study with a marked difference in erodability between bare sediment and the high $Z$. noltii density, but the present study does not allow the sediment stabilising role of $Z$. noltii roots/rhizome system (i.e. in the absence of above ground vegetation) to be assessed. However, the erosion curves of the high density $Z$. noltii (Fig. 7) indicate rapid erosion of the underly- 
ing sediment once the microphytobenthos and surface sediment has been resuspended (i.e. $>0.34 \mathrm{~m} \mathrm{~s}^{-1}$ ). While the role of $Z$. noltii rhizomes on sediment stability still needs to be quantified, there was no evidence that the shoots or the roots of $Z$. marina had any effect on sediment stability of the muddy site.

Bed shear stress was not enhanced by the Zostera noltii at lower current speeds of $<0.1 \mathrm{~m} \mathrm{~s}^{-1}$ (Fig. 4) when the values for $\tau_{0}$ were $<0.06 \mathrm{~Pa}$. Therefore, there was no significant enhancement of turbulence that might increase sediment erodability or hinder settling of fine particles under calm and slack water conditions. This is consistent with the observations of Worcester (1995), who showed that at low $Z$. marina densities (100 to 200 shoots $\left.\mathrm{m}^{-2}\right)$ and low current speeds $\left(<0.05 \mathrm{~m} \mathrm{~s}^{-1}\right)$, there was reduced advection but no effect on turbulent mixing relative to areas without seagrass. The greatest effects of $Z$. noltii seagrass beds on flow occurred at the highest shoot density and at the highest flows. This was similar to effects recorded by Fonseca et al. (1982) and Gambi et al. (1990) for the larger $Z$. marina. As ambient current velocities decreased to $<0.12 \mathrm{~m} \mathrm{~s}^{-1}$, the amount of flow reduction by seagrass also decreased substantially. Gambi et al. (1990) recorded skimming flow at low flows of only $0.05 \mathrm{~m} \mathrm{~s}^{-1}$ at high shoot densities, whereas the lower densities studied in the field by Worcester (1995) showed no evidence of skimming flow.

In addition to the biological interactions between microphytobenthos and seagrass beds, suspension feeding cockles are often associated with seagrass beds. The filtering activity of the high densities of cockles Cerastoderma edule, found at the sheltered muddy site with Zostera marina, are likely to enhance sedimentation of suspended particulates and improve water clarity. A model has demonstrated that suspension feeding oysters have a greater impact on water clarity in comparison to the reduced sediment resuspension due to wave attenuation by high density seagrass beds (Newell \& Koch 2004). There is also evidence of a cascading effect of hydrodynamics on an epiphyte-grazer system in intertidal seagrass beds (Schanz et al. 2002). The snails Hydrobia ulvae grazing on $Z$. noltii showed a negative correlation with current speed, whereas epiphyte biomass showed a significant positive correlation with current speed. Higher flow resulted in a reduction in grazing due to snails being washed off the shoots and this led to enhanced epiphytic growth, which inhibited seagrass development. Schanz et al. (2002) therefore proposed that hydrodynamic forces may act as a top-down regulator in seagrass communities with lower seagrass biomass, in part due to the dense epiphyte layer resulting from the absence of grazers at the more exposed sites.

Hydrodynamic forces have a strong impact on all levels of biological organisation in seagrass beds from a species to an ecosystem level. Material exchange between sediments and water is accelerated under high currents and turbulence. In this way, hydrodynamics act as a bottom-up regulator. Studies of the important interactions between hydrodynamics, benthic-pelagic coupling, and the resulting effects on the trophic web will improve our understanding of the role of hydrodynamic forces in coastal ecosystems.

Acknowledgements. This study was part funded by the EU Bioflow project (Contract No. EVR1-CT-2001-20008) and the Natural Environment Research Council Core Research Programme at the Plymouth Marine Laboratory.

\section{LITERATURE CITED}

Ackerman JD (1986) Mechanistic implications for pollination in the marine angiosperm Zostera marina. Aquat Bot 24:343-353

Amos CL, Bergamasco A, Umgiesser G, Cappucci S and others (2004) The stability of tidal flats in Venice Lagoon: the results of in-situ measurements using two benthic, annular flumes. J Mar Syst 51:211-241

Asmus H, Asmus R (2000) Material exchange and food web of seagrass beds in the Sylt-Rømø Bight: How significant are community changes at the ecosystem level? Helgol Mar Res 54:137-150

Bouma TJ, De Vries MB, Low E, Peralta G, Tánczos IC, Van de Koppel J, Herman PMJ (2005) Trade-offs related to ecosystem engineering: a case study on stiffness of emerging macrophytes. Ecology 86:2187-2199

Cabaco S, Santos R (2007) Effects of burial and erosion on the seagrass Zostera noltii. J Exp Mar Biol Ecol 340:204-212

Decho AW (2000) Microbial biofilms in intertidal systems: an overview. Cont Shelf Res 20:1257-1273

de Jonge VN, Essink K, Boddeke R (1993) The Dutch Wadden Sea: a changed ecosystem. Hydrobiologia 265:45-71

Eckman JE (1987) The role of hydrodynamics in recruitment, growth, and survival of Argopecten irradians (L) and Anomia simplex (D'Orbigny) within eelgrass meadows. J Exp Mar Biol Ecol 106:165-191

Fonseca MS (1983) Comparisons of current flow and wave dynamics through four seagrass species. Estuaries 6:257-258

Fonseca MS (1996) The role of seagrasses in nearshore sedimentary processes: a review. In: Nordstrom $\mathrm{K}$, Roman CT (eds) Estuarine shores: evolution, environments and human alterations. John Wiley, London, p 261-286

Fonseca MS, Bell SS (1988) Influence of physical setting on seagrass landscapes near Beaufort, North Carolina, USA. Mar Ecol Prog Ser 171:109-121

Fonseca MS, Fisher JS (1986) A comparison of canopy friction and sediment movement between four species of seagrass with reference to their ecology and restoration. Mar Ecol Prog Ser 29:15-22

Fonseca MS, Kenworthy WJ (1987) Effects of current on photosynthesis and distribution of seagrasses. Aquat Bot 27:59-78

Fonseca MS, Fisher JS, Zieman JC, Thayer GW (1982) Influence of the seagrass, Zostera marina L., on current flow. Estuar Coast Shelf Sci 15:351-364

$>$ Fonseca MS, Koehl MAR, Kopp BS (2007) Biomechanical factors contributing to self-organisation in seagrass landscapes. J Exp Mar Biol Ecol 340:227-246

Friend PL, Ciavola P, Cappucci S, Santos R (2003a) Bio- 
dependent bed parameters as a proxy tool for sediment stability in mixed habitat intertidal areas. Cont Shelf Res 23:1899-1917

Friend PL, Collins MB, Holligan PM (2003b) Day-night variation of intertidal flat sediment properties in relation to sediment stability. Estuar Coast Shelf Sci 58:663-675

- Gacia E, Duarte CM (2001) Sediment retention by a Mediterranean Posidonia oceanica meadow: the balance between deposition and resuspension. Estuar Coast Shelf Sci 52: 505-514

> Gacia E, Granata TC, Duarte CM (1999) An approach to measurement of particle flux and sediment retention within seagrass (Posidonia oceanica) meadows. Aquat Bot 65:255-268

Gambi MC, Nowell ARM, Jumars PA (1990) Flume observations on flow dynamics in Zostera marina (eelgrass) beds. Mar Ecol Prog Ser 61:159-169

> Granata TC, Serra T, Colomer J, Casamitjana X, Duarte CM, Gacia E (2001) Flow and particle distributions in a nearshore seagrass meadow before and after a storm. Mar Ecol Prog Ser 218:95-106

Heiss WM, Smith AM, Probert PK (2000) Influence of the small intertidal seagrass Zostera novazelandica on linear water flow and sediment texture. N Z J Mar Freshw Res 34:689-694

Koch EW (1994) Hydrodynamics, diffusion-boundary layers and photosynthesis of the seagrasses Thalassia testudinum and Cymodocea nodosa. Mar Biol 118:767-776

Koch EW (1999) Sediment resuspension in a shallow Thalassia testudinum banks ex Konig bed. Aquat Bot 65:269-280

Koch EW, Gust G (1999) Water flow in tide- and wavedominated beds of the seagrass Thalassia testudinum. Mar Ecol Prog Ser 184:63-72

Lucas CH, Widdows J, Brinsley MD, Salkeld PN, Herman PMJ (2000) Benthic-pelagic exchange of microalgae at a tidal flat. 1. Pigment analysis. Mar Ecol Prog Ser 196: 59-73

Madsen JD, Chambers PA, James WF, Koch EW, Westlake DF (2001) The interaction between water movement, sediment dynamics and submersed macrophytes. Hydrobiologia 444:71-84

Newell RIE, Koch EW (2004) Modeling seagrass density and distribution in response to changes in turbidity stemming from bivalve filtration and seagrass sediment stabilization. Estuaries 27:793-806

Orth RJ (1977) The importance of sediment stability in seagrass communities. In: Coull BC (ed) Ecology of marine benthos. University of South Carolina Press, Columbia, SC, p 281-300

> Orvain F, Sauriau PG, Sygut A, Joassard L, Le Hir P (2004) Interacting effects of Hydrobia ulvae bioturbation and microphytobenthos on the erodibility of mudflat sediments. Mar Ecol Prog Ser 278:205-223

Paterson DM (1989) Short-term changes in the erodibility of intertidal cohesive sediments related to the migratory behaviour of epipelic diatoms. Limnol Oceanogr 34:223-234

Paterson DM, Black KS (1999) Water flow, sediment dynamics and benthic biology. Adv Ecol Res 29:155-193

> Peralta G, Brun FG, Hernandez I, Vergara JJ, Perez-Llorens JL (2005) Morphometric variations as acclimation mechanisms in Zostera noltii beds. Estuar Coast Shelf Sci 64: 347-356

Peralta G, Brun FG, Pérez-Lloréns JL, Bouma TJ (2006) Direct effects of current velocity on the growth, morphometry and architecture of seagrasses: a case study on Zostera

Initial editorial responsibility: Howard Browman, Storebø, Norway (until November 5, 2007); Final editorial responsibility: Matthias Seaman, Oldendorf/Luhe, Germany noltii. Mar Ecol Prog Ser 327:135-142

Peterson CH, Luettich RA, Micheli F, Skilleter GA (2004) Attenuation of water flow inside seagrass canopies of differing structure. Mar Ecol Prog Ser 268:81-92

Pope ND, Widdows J, Brinsley MD (2006) Estimation of bed shear stress using the turbulent kinetic energy approach: a comparison of annular flume and field data. Cont Shelf Res 26:959-970

Rhoads DC, Boyer L (1982) The effects of marine benthos on physical properties of sediments: a successional perspective. In: McCall PL, Tevesz MJS (eds) Animal-sediment relations: the biogenic alteration of sediments, Vol 2 . Plenum Press, New York, NY, p 3-52

Schanz A, Asmus H (2003) Impact of hydrodynamics on development and morphology of intertidal seagrasses in the Wadden Sea. Mar Ecol Prog Ser 261:123-134

Schanz A, Polte P, Asmus H (2002) Cascading effects of hydrodynamics on an epiphyte-grazer system in intertidal seagrass beds of the Wadden Sea. Mar Biol 141:287-297

Stapleton KR, Huntley DA (1995) Seabed stress determinations using the inertial dissipation method and the turbulent kinetic energy method. Earth Surf Process Landf 20:807-815

Sutherland TF, Amos CL, Grant J (1998) The effect of buoyant biofilms on the erodibility of sublittoral sediment of a temperate microtidal estuary. Limnol Oceanogr 43:225-235

Underwood GJC, Paterson DM, Parkes RJ (1995) The measurement of microbial carbohydrate exoploymers from intertidal sediments. Limnol Oceanogr 40:1243-1253

van Keulen M, Borowitzka MA (2002) Comparison of water velocity profiles through morphologically dissimilar seagrasses measured with a simple and inexpensive current meter. Bull Mar Sci 71:1257-1267

Ward LG, Kemp WM, Boynton WR (1984) The influence of waves and seagrass communities on suspended particulates in an estuarine embayment. Mar Geol 59:85-103

Widdows J, Brinsley MD (2002) Impact of biotic and abiotic processes on sediment dynamics and the consequences to the structure and functioning of the intertidal zone. J Sea Res 48:143-156

Widdows J, Brinsley MD, Bowley N, Barrett C (1998) A benthic annular flume for in situ measurement of suspension feeding/biodeposition rates and erosion potential of intertidal cohesive sediments. Estuar Coast Shelf Sci 46: $27-38$

Widdows J, Brinsley MD, Salkeld PN, Lucas CH (2000a) Influence of biota on spatial and temporal variation in sediment erodability and material flux on a tidal flat (Westerschelde, The Netherlands). Mar Ecol Prog Ser 194:23-37

Widdows J, Brown S, Brinsley MD, Salkeld PN, Elliott M (2000b) Temporal changes in intertidal sediment erodability: influence of biological and climatic factors. Cont Shelf Res 20:1275-1289

- Widdows J, Brinsley MD, Pope ND, Staff FJ, Bolam SG, Somerfield PJ (2006) Changes in biota and sediment erodability following the placement of fine dredged material on upper intertidal shores of estuaries. Mar Ecol Prog Ser 319:27-41

Widdows J, Friend PL, Bale AJ, Brinsley MD, Pope ND, Thompson CEL (2007) Inter-comparison between five devices for determining erodability of intertidal sediments. Cont Shelf Res 27:1174-1189

Worcester SE (1995) Effects of eelgrass beds on advection and turbulent mixing in low current and low shoot density environments. Mar Ecol Prog Ser 126:223-232 